Revista Eletrônica de Ciência Administrativa (RECADM) - ISSN 1677-7387

Faculdade Cenecista de Campo Largo - Coordenação do Curso de Administração

v. 3, n. 2, nov./2004 - http://revistas.facecla.com.br/index.php/recadm/

\title{
CENÁRIOS PROSPECTIVOS: FERRAMENTAS ESTRATÉGICAS PARA OBTENÇÃO E MANUTENÇÃO DA VANTAGEM COMPETITIVA DAS ORGANIZAÇÕES
}

Henrique Martins Rocha ${ }^{1}$

\section{RESUMO}

A complexidade de gerir uma organização no contexto atual, onde mudanças e exigências dos clientes são cada vez mais dinâmicas com a competição cada vez mais acirrada, despertou a necessidade de uma avaliação dos possíveis futuros alternativos. Na busca de um sistema que permitisse às organizações uma orientação correta dentro desta nova realidade, surgiram os estudos de cenários prospectivos, uma metodologia utilizada para listar as possibilidades existentes, ampliando a capacidade das organizações proporem e monitorarem suas ações estratégicas, de forma a permitir o atingimento e manutenção de posições competitivas. O presente trabalho visa estudar essa metodologia, reunindo informações e descrevendo os principais conceitos relacionados ao assunto. As conclusões do trabalho indicam que o método mostra-se uma ferramenta que pode auxiliar a definir a estratégia da organização, permitindo ao mesmo tempo, uma posição mais flexível e apropriada para lidar com a incerteza e o novo, tornando-a mais robusta no posicionamento estratégico.

Palavras chave: Cenários, competitividade, estratégia,

\section{ABSTRACT}

The complexity of managing a organization nowadays, whereby changes and customer demands are increasingly more dynamic, and the competition is tougher than ever, brought about a need for a reevaluation based on alternative futures. In search of a system, which would enable the companies to sail forth in a correct direction, within this new reality, arose the prospective scenarios study, which is a methodology whereby futures are identified, expanding the possibility of the organizations to propose and to monitor their strategic actions, in order to enable the achievement and/or maintenance of competitive positions. This present work has the intent of perform an in-deep study of this methodology, gathering information and describing the main concepts related to it. The conclusion indicates that the referred method may help defining the organization strategy, and which may enable it to have a more flexible and adequate position to manage the uncertainness, becoming more robust and strategically better positioned.

Key words: competitiveness, scenarios, strategy

\section{INTRODUÇÃO}

Marcial (1999) cita que desde os primórdios da sua existência, o homem procura respostas para suas indagações. Entender o que está ocorrendo, suas causas e conseqüências, e tentar descobrir o que 


\section{Revista Eletrônica de Ciência Administrativa (RECADM) - ISSN 1677-7387 Faculdade Cenecista de Campo Largo - Coordenação do Curso de Administração v. 3, n. 2, nov./2004 - http://revistas.facecla.com.br/index.php/recadm/}

irá acontecer fazem parte da existência humana. $\mathrm{O}$ instinto de sobrevivência conduz o homem a buscar estas respostas, com o intuito de minimizar as incertezas que o rodeiam, procurando assim garantir a sua sobrevivência por um período mais longo de tempo. Conforme Davis (1998), muitos tentam entender o futuro puramente através da previsão, extrapolando os padrões vistos no passado para o futuro e tendem a negligenciar o fato de que uma tendência é válida até que surja uma descontinuidade e ela se rompa. Estas rupturas são as que trazem maior risco, mas que também oferecem as maiores oportunidades. Via de regra, os gerentes não consideram - ou subestimam a probabilidade de - mudanças radicais ou descontínuas que poderiam ser improváveis, mas que alterariam significativamente a estrutura industrial ou a vantagem competitiva de uma empresa (PORTER, 1989). Grandes descontinuidades são características de virtualmente todo tipo de progressão evolutiva. Segundo Barros (2000), as empresas não conseguem prever ou gerenciar a descontinuidade, pois geralmente os produtos se apropriam de tecnologias diferentes, oriundas do desenvolvimento de outras ciências, possibilitando a criação de um produto que substituirá com vantagem adicional o produto existente. As transições tecnológicas, alem de provocar o desaparecimento de produtos, resultam na exclusão de setores produtivos inteiros. Assim, os lideres da tecnologia atual raramente sobrevivem para se tornarem lideres da nova tecnologia.

Davis (2002a) cita que há a necessidade de fazer escolhas para o futuro, escolhas estas que afetarão os empregados, clientes, comunidades ao redor e acionistas. As escolhas podem ser, por exemplo, aonde investir, que habilidades desenvolver, que tipo de inovação perseguir e que tipo de novas escolhas oferecer aos clientes. Há a necessidade de se fazer isso para um futuro que é desconhecido, mas não impensável. A prospecção exige um aparato de conhecimentos que transcende o campo disciplinar: primeiramente, deve-se considerar as interação dos múltiplos interesses e limitações dos diversos atores do processo e os conflitos aí envolvidos, cujas causas são determinadas no campo das ciências biológicas, físicas, químicas, sociais e econômicas (BRASIL, [2001?]). Diferentemente de outras formas de análise estratégica, os cenários permitem considerar elementos significativos que são difíceis de medir e prever - como estórias que descrevem, mas também ajudam a formar, a história de um país e sua cultura (SHELL INTERNATIONAL, 2002).

Segundo Porter (1989), algumas empresas constróem planos de contingência como parte do processo de planejamento estratégico, numa tentativa de testarem estratégias em relação a grandes fontes de incerteza, O planejamento de contingência é, porém, raro na prática, e geralmente testam estratégias incrementalmente relativas a apenas uma ou duas incertezas básicas, como índice de inflação ou preço do petróleo. Estes planos raramente examinam estruturas industriais futuras alternativas, ou compelem os gerentes a considerar suas implicações.

Os cenários prospectivos estão mais relacionados ao pensamento estratégico do que ao planejamento estratégico, olhando além de nossas limitações, reconhecendo que existem muitas visões do mundo diferentes das nossas. Os cenários nos permitem ter uma melhor compreensão da vulnerabilidade das corporações e as possibilidades para um novo posicionamento estratégico (DAVIS, 1998), usualmente não lidando com as preocupações operacionais do negócio. A função dos

\footnotetext{
${ }^{1}$ Professor da Associação Educacional Dom Bosco. Mestrando do Laboratório de Tecnologia, Gestão de
} 
cenários não é acertar eventos futuros, mas considerar as forças que podem direcionar o futuro por determinados caminhos, ajudando os gerentes a compreender a dinâmica do ambiente de negócios, reconhecer novas possibilidades, avaliar opções estratégicas e decisões de longo prazo (SHELL INTERNATIONAL, 2001).

Porter (1989) cita que os cenários objetivam reduzir as chances de que ações adotadas para se lidar com um elemento da incerteza em uma indústria piorem involuntariamente a posição desta em relação a outras incertezas. Cita ainda que os cenários são um dispositivo poderoso para se levar em conta a incerteza, ao se fazerem escolhas estratégicas. Eles permitem que uma empresa se afaste de previsões perigosas de um único ponto do futuro em casos em que este não pode ser previsto.

Diversas organizações encontram dificuldades de lidar com o dilema de antecipar-se às mudanças e tendências, movimento necessário à obtenção e manutenção de suas posições competitivas, não tendo completo domínio sobre as diversas variáveis que afetam sua estrutura, seu mercado, seus processos e o mundo como um todo. Ainda que algumas mudanças possam ser antecipadas, essa não é a situação geral, o que leva as organizações a, muitas vezes, tomarem decisões estratégicas sem uma base apropriada de sustentação. Sendo o futuro algo incerto e que sobre o qual tem-se controle limitado, a presente pesquisa busca contribuir com o campo de proposição e monitoramento de estratégias competitivas, mais especificamente, com a disciplina "cenários prospectivos", por meio da apresentação, teorização e reflexão de alguns dos principais conceitos sobre o tema. Tem-se como hipótese a redução da incerteza e aumentando a probabilidade de sucesso das organizações através da utilização de cenários prospectivos como instrumentos de proposição e monitoramento de estratégias competitivas.

\section{DESENVOLVIMENTO}

A investigação realizada neste trabalho fundamenta-se teoricamente na área de proposição e monitoramento de estratégias competitivas, mais especificamente, cenários prospectivos. Buscou-se na bibliografia vários autores, que se preocuparam em estudar o assunto. Autores como Porter (1989), Davis (1998 e 2002), Bethlen (1999), Marcial (1999 e 2001), Godet (2000), Van Der Heijden (2000), Buarque (2003) e outros, fizeram vários estudos empíricos e teóricos, contribuindo para um maior entendimento sobre o tema.

Conforme Marcial (1999), afora ações isoladas, iniciadas ainda na idade Renascentista de prever o futuro, somente em 1902, com a publicação do livro "O Descobrimento do Futuro" de George Wells, encontra-se a associação de fatos já conhecidos com o futuro. As técnicas de previsão clássica, baseadas em modelos matemáticos, começaram a surgir no período pós-guerra, sendo que os aspectos relacionados à incerteza só posteriormente começaram a fazer parte destes estudos. Um forte salto foi dado pela RAND Corporation, que estendeu suas atividades para os campos da sociologia, meteorologia e política. Diversos autores reconhecem Herman Kahn, que atuou na RAND durante os anos 50, como o introdutor do conceito de cenários prospectivos, quando fundou o Hudson Institute e publicou em 1967 seu livro "The Year 2000". 
A Shell desenvolve cenários prospectivos desde a década de 70 , com o trabalho do francês Pierre Wack, mas em meados da década de 80 , tornou-se mais popular, com a publicação da história de sucesso da Shell na Harvard Business Review. Michael Porter e Peter Schwarts se aprofundam também no tema, mas é em 1987 que Michel Godet publica seu livro "Scenarios and Strategic Management", considerado pela maioria dos autores como um marco na história dos métodos de desenvolvimento de cenários prospectivos. Em 1988 surge a Global Business Network (GBN), empresa de prospectiva criada por Peter Schwartz e Pierre Wack (GODET \& ROUBELAT, 2000 e MARCIAL, 1999).

No Brasil, encontra-se à partir do final da década de 80 , algumas práticas de cenários, principalmente na área de energia, além de alguns estudos do BNDES e Secretaria ou Ministério do Planejamento.

O ponto comum encontrado na pesquisa dos diversos autores indica que, se por um lado há a necessidade estratégica das organizações pensarem adiante, procurando antecipar-se ao futuro, preparando-se para um posicionamento estratégico adequado, que dê sustentação ao alcance desse posicionamento e manutenção do mesmo, resta a dúvida de como se preparar para o que é desconhecido e incerto, criando um dilema de difícil solução.

A utilização de cenários prospectivos é entendida como uma forma apropriada de resolver este dilema: ainda que o futuro seja incerto, ao exercitar as possibilidades existentes, a organização pode visualizar como ela se enquadraria - afetando e sendo afetada pelas potenciais circunstâncias dos diferentes futuros, Ao agir desta forma, a organização diminui a possibilidade de surpresas, ao deparar-se com futuros que possam ter sido pensados antes. No entanto, há necessidade deste exercício ser apropriadamente conduzido, de forma a não criar limites que podem não existir o mundo real: um futuro que possa ser hoje considerado impossível, tomando como base nosso conhecimento atual e nossa cultura, pode se mostrar viável num momento seguinte, por conta de alguma descoberta e/ou mudança estrutural.

Da mesma forma, os autores alertam que a função básica do exercício de geração de cenários não é conseguir acertar os mesmos na íntegra, mas expandir os horizontes. Roubelat (2002), apud Vásquez (2003) expõe algumas correntes e disciplinas na área de estudos sobre o futuro, conforme o quadro a seguir:

\begin{tabular}{|l|l|l|l|}
\hline \multicolumn{1}{|c|}{ Corrente } & \multicolumn{1}{|c|}{$\begin{array}{c}\text { Autores } \\
\text { Representativos }\end{array}$} & $\begin{array}{c}\text { Disciplinas ou Campos de } \\
\text { Investigação }\end{array}$ & \multicolumn{1}{c|}{ Período } \\
\hline Futurologia & Flechtheim, Bell & $\begin{array}{l}\text { História, } \\
\text { Sociologia }\end{array}$ & Anos 40 - anos 60 \\
\hline $\begin{array}{l}\text { Antropologia } \\
\text { Prospectiva }\end{array}$ & Berger & Filosofia & Anos 50 \\
\hline Pesquisa de Futuro & Helmer, Enzer & Investigação Operacional & Anos 60 \\
\hline Estratégia Prospectiva & Poirier & Estratégia Militar & Anos 60 \\
\hline Previsão Tecnológica & Linstone & Engenharia & Anos 70 \\
\hline Prospectiva Estratégica & Godet, Lesoume & $\begin{array}{l}\text { Ciências de Gestão, } \\
\text { Ciência Econômica }\end{array}$ & Anos 70 e \\
\hline Estudos de Futuros & $\begin{array}{l}\text { Masini, Bell, Dator, } \\
\text { De Jouvenel }\end{array}$ & $\begin{array}{l}\text { Sociologia, } \\
\text { Ciências Políticas }\end{array}$ & Anos 70 \\
\hline $\begin{array}{l}\text { Antevisão de } \\
\text { Tecnologia }\end{array}$ & Martin, Miles & Ciência Econômica & $\begin{array}{l}\text { Fim dos anos 80 e } \\
\text { anos } 90\end{array}$ \\
\hline
\end{tabular}




\section{Revista Eletrônica de Ciência Administrativa (RECADM) - ISSN 1677-7387 Faculdade Cenecista de Campo Largo - Coordenação do Curso de Administração v. 3, n. 2, nov./2004 - http://revistas.facecla.com.br/index.php/recadm/}

Quadro 1: Metodologia Prospectiva e Pesquisa em Gerenciamento Estratégico - fonte: Roubelat (2002) apud Vásquez (2003)

Willians (2003) cita que a construção de cenários é uma ferramenta poderosa para interrogar o pensamento futuro e para discutir o futuro, enquanto este cria uma gama de alternativas para consideração. Conforme Godet (2000), o desenvolvimento não depende somente da lógica, mas também das emoções e comportamento humano. Segundo Porter (1989), a construção de um cenário útil envolve o desenvolvimento de uma lógica para o modo como os vários elementos da estrutura industrial se inter-relacionam, separando variáveis de cenário verdadeiras de mudanças predeterminadas e dependentes na indústria. Um cenário deve procurar expor efeitos de segunda ordem das mudanças estruturais resultantes de uma mudança na indústria que afeta outras. Conforme Masini \& Vasquez (2000), a construção de cenários é um processo de alinhamento, porque combina, por exemplo, história, sociologia, psicologia de grupo e estatística. Roubelat (2000) cita que a maioria das atividades de "pensamento futuro" prevêem largamente o contato entre o conhecimento complementar e o diferencial, com abordagem normalmente descrita como multi-disciplinária e sistêmica.

De acordo com Godet (2000), a incerteza do futuro pode ser avaliada através de um número de possíveis cenários, dentro do campo de probabilidades, mas a experiência mostra que, em geral, um terço do total de cenários possíveis é suficiente para cobrir $80 \%$ do campo de probabilidades. Os cenários são baseados em intuições, mas desenvolvidos como estruturas analíticas (SHELL INTERNATIONAL, 2003).

Davis (1998 e 2002a) expõe que a construção de cenários para uma organização requer clareza sobre o foco ou tema que se estuda. Quando o foco ou tema já foi definido, as principais áreas de pesquisa são identificadas e a informação coletada. O próximo passo é identificar as forças direcionadoras que vão desenhar o ambiente futuro: o que vai permanecer e pode ser previsto (por exemplo, estudos demográficos) e o que é desconhecido.

Conforme Davis (2002b), o processo de construção de cenários cria um "espaço futuro", no qual as partes envolvidas (stakeholders) podem dividir suas perspectivas, disseminar e incentivar o aprendizado, criar novos entendimentos e explorar diferentes opções, catalizando a abordagem de parceria, envolvendo os setores privados e organizações não governamentais e outros envolvidos, desenvolvendo o debate público e facilitando a comunicação e entendimento entre diferentes partes. Havendo a necessidade de planejar o futuro, precisamos criar uma visão que compreenda o contexto no qual operamos. Mas não é possível fazer isso sozinhos de forma efetiva: nossos "pontos cegos" impõe limitações no nosso entendimento e percepção e, desta forma, precisamos combinar nossos conhecimentos e pensamentos com o de outros.

O estudo envolveu inicialmente a obtenção de informações teóricas, através de estudo exploratório e, a partir dessa, a formulação de hipóteses, seguido do estudo formal descritivo, calcado numa pesquisa bibliográfica junto a autores consagrados na abordagem do tema tratado, além da leitura de artigos específicos sobre o assunto existentes no mercado, com a finalidade de levantar os conceitos sobre cenários, cenários prospectivos, estratégias competitivas, inteligência competitiva, etc. Dessa forma, fez-se uso de livros, revistas, jornais, dissertações e teses, documentos impressos ou inseridos 
em meios eletrônicos, e vários tipos de comunicados científicos, entre outros, relativos à temática. Definiu-se o público-alvo - autoridades especialistas - e elaborou-se o questionário e roteiro da entrevista, conduzido por processo interrogatório, análise comparativa e interpretação dos resultados, num estudo ex post facto, seguido da consolidação do tema nas diversas abordagens já publicadas.

Conforme Marcial (1999), um cenário completo contém seis componentes principais:

1. Título - os nomes dados devem dar a idéia lógica dos cenários, condensando a essência da estória escrita, servindo como lembrança ou referência de um cenário específico;

2. Filosofia - sintetiza o movimento ou a direção fundamental do sistema considerado;

3. Variáveis - representam aspectos ou elementos relevantes do sistema ou do contexto considerado, face ao objetivo a que se destina o cenário;

4. Atores - indivíduos, grupos, decisores, organizações ou associações de classes que influenciam ou recebem influência significativa do sistema e/ou contexto considerado no cenário;

5. Cenas - visão da situação considerada em um determinado instante do tempo, a qual descreve como estão organizados ou vinculados entre si os atores e as variáveis neste instante;

6. Trajetória - percurso ou caminho que o sistema seguirá no horizonte de tempo considerado. Descreve o movimento ou a dinâmica deste sistema, a partir da cena inicial até a cena final.

Segundo Davis (1998), cenários devem atender os seguintes requerimentos:

1. Devem ser construídos a partir do presente e serem reconhecíveis pelos usuários, devendo haver relação com sinais do momento presente;

2. Não devem ser facilmente descartados pelos usuários, sendo plausíveis aos seus olhos;

3. Devem ser baseados em análises e internamente consistentes;

4. Somente quando os cenários desafiam os mapas mentais é que a possibilidade de aprendizado existe;

5. Para serem de uso direto, devem implicar em conseqüências diretas para as decisões dos usuários.

Diversos modelos / metodologias para elaboração de cenários são encontrados da literatura especializada, como o modelo de Porter (1989), Grumbach (BRAINSTORMING, 2003), GBN (ZUMBLE, 2000) e Godet (GODET et al, 1999, GODET, 2000 e BUARQUE, 2003). Sobre este último, alguns de seus passos e ferramentas utilizadas estão detalhados a seguir:

O método desenvolvido por Godet propõe uma análise estruturada, utilizando ferramentas que auxiliam a obter condições de relevância, coerência, plausividade e transparência. O modelo do método pode ser observado a seguir: 


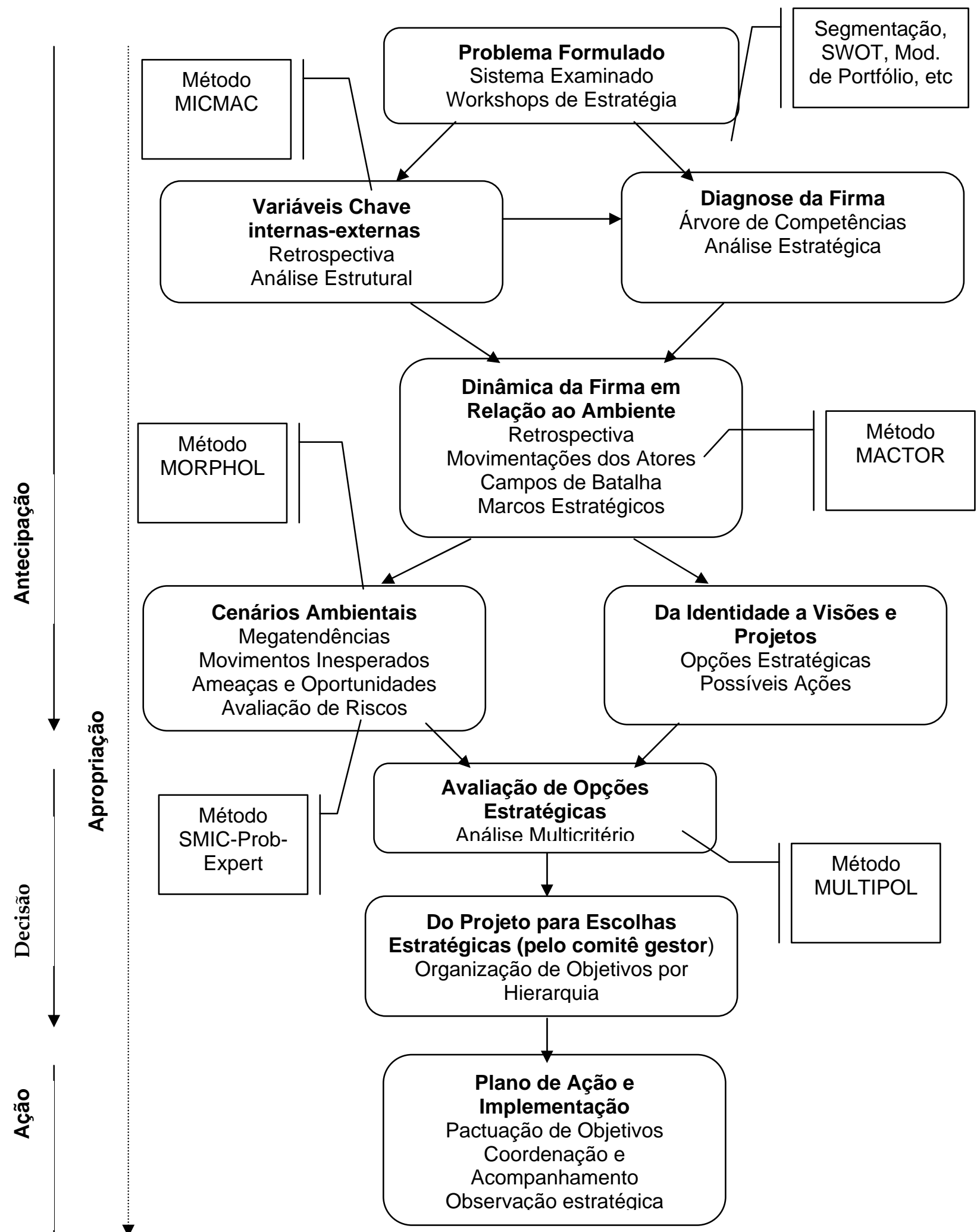

Figura 1: Método de Godet (Fonte: adaptado de Godet (1994), apud Arcade et al (2003) 
A primeira fase do método busca analisar o problema e definir o sistema examinado, sendo necessário posicionar o processo prospectivo em seu contexto sócio-organizacional, de forma a introduzir e simular todo o processo prospectivo.

A esta fase, segue-se um raio-X completo da firma, desde o know-how às linhas de produto, utilizando-se metodologias como segmentação, análise de ciclos de vida, curvas de aprendizado, modelos de portfólio, análise da cadeia de valor, etc. São então identificadas as variáveis internas e externas à firma, utilizando-se a ferramenta chamada MICMAC - Matriz de Impacto Cruzado e Multiplicação Aplicada, a qual baseia-se no princípio de interações entre variáveis: como se pode observar no desenho esquemático a seguir, se A influencia C e B; e se B influencia C, a soma de dependências de $C$ é maior do que a influência exercida nela por $A$ e por $B$, visto que a influência total de A sobre $C$ inclui a influência "indireta" exercida através de B.

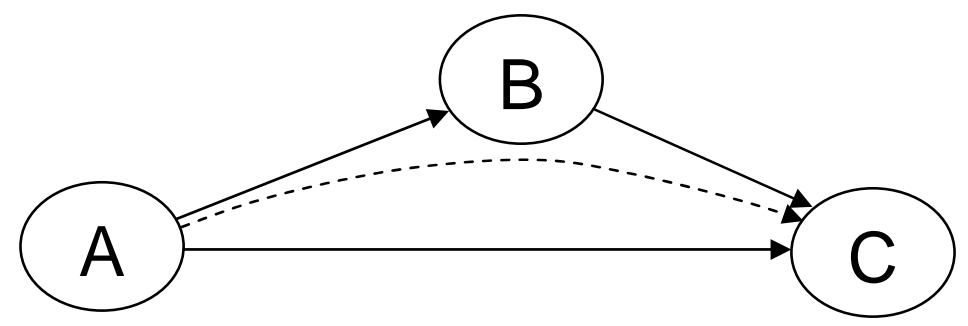

Figura 2: Fluxo de influências (fonte: adaptado de Buarque, 2003)

Desta forma, o método MICMAC estabelece que as diversas variáveis identificadas sejam colocadas numa matriz de dupla entrada, aonde são estabelecidos valores numéricos entre elas - influência "de" e "sobre". Desta forma, o verdadeiro peso de influência que cada variável tem sobre o cenário e a organização pode ser identificado, levando-se em consideração as interações entre elas, como pode ser visto no quadro abaixo:

\begin{tabular}{|c|c|c|c|c|c|c|c|}
\hline \multicolumn{2}{|c|}{ Influência } & \multicolumn{6}{|c|}{ VARIÁVEIS } \\
\hline \multicolumn{2}{|c|}{ DE / SOBRE } & A & $B$ & $\mathrm{C}$ & $\ldots$ & $\mathrm{n}$ & $\sum$ \\
\hline \multirow{6}{*}{ 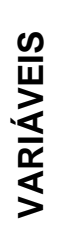 } & $\mathrm{A}$ & & 1 & & & & \\
\hline & $B$ & 1 & & 3 & & & \\
\hline & $\mathrm{C}$ & & & & & & \\
\hline & $\ldots$ & & & & & & \\
\hline & $\mathrm{N}$ & & 1 & & & & \\
\hline & $\sum$ & & & & & & \\
\hline
\end{tabular}

Quadro 2: Matriz MICMAC (elaboração dos autores)

Na fase seguinte, utiliza-se também uma matriz de entrada dupla, buscando identificar e mensurar os movimentos dos diversos atores envolvidos, com relação aos diversos objetivos e o poder de influência direta e indireta - interações - entre eles. Esta metodologia, chamada MACTOR - Matriz de Alianças e Conflitos: Táticas, Objetivos e Recomendações, busca quantificar as ações dos atores envolvidos sobre os outros atores e, em paralelo, quantificar o posicionamento dos diversos atores contra os diversos potenciais objetivos - também colocados numa matriz. Ao efetuar-se a multiplicação destas 2 matrizes, obtém-se uma matriz resultante, a qual indica, através de seus somatórios, o poder de influência dos atores, tanto no que tange às convergências, quanto às divergências. 


\section{Revista Eletrônica de Ciência Administrativa (RECADM) - ISSN 1677-7387 Faculdade Cenecista de Campo Largo - Coordenação do Curso de Administração v. 3, n. 2, nov./2004 - http://revistas.facecla.com.br/index.php/recadm/}

De posse destas informações, inicia-se a fase seguinte, voltada à construção dos cenários propriamente ditos. Busca-se reduzir a incerteza existente nas questões chave para o futuro, utilizando metodologias diversas, tais como o Método MORPHOL e o método SMIC-Prob-Expert. O primeiro, derivado de Morphological Analysis (morfologia: estudo das estruturas e das formas), busca inicialmente criar os possíveis cenários para as diversas incertezas listadas. Estes cenários, gerados a partir de entrevistas com especialistas, brainstorming, pelo método Delphi (metodologia de busca de consenso entre especialistas, com questionamentos direcionados e análise estatísticas das respostas em rodadas sucessivas) e outros mais, são carregados numa matriz, como o exemplo a seguir:

\begin{tabular}{|c|c|c|c|c|}
\hline INCERTEZAS & I & II & III & $\ldots$ \\
\hline A & & & & \\
\hline B & & & & \\
\hline C & & & & \\
\hline$\ldots$ & & & & \\
\hline
\end{tabular}

Quadro 3: Matriz de Impactos Cruzados (fonte: adaptado de Buarque, 2003)

Após a montagem da matriz - que pode ser através de software específico - têm-se identificados os diversos potenciais cenários para cada incerteza, ou seja: Al, All, AllI,.., BI, BII, etc. Inicia-se então a avaliação das possíveis composições destes cenários - $\mathrm{Al}, \mathrm{BI}, \mathrm{Cl}, \ldots ; \mathrm{Al}, \mathrm{BII}, \mathrm{Cl}, \ldots$; $\mathrm{Al}, \mathrm{BII}, \mathrm{Cll}, \ldots$, etc., sendo que, esta avaliação é seletiva, ou seja, os "caminhos" são avaliados descendentemente, a partir do nível mais alto da matriz e, ao encontrarem-se combinações improváveis ou inconsistentes como, por exemplo, se Al e BI não poderem coexistir - os caminhos são descartados. Assim sendo, ao final de uma análise de uma matriz de $\mathrm{x}$ incertezas por $\mathrm{n}$ futuros gerará uma quantidade de cenários coerentes que é menor do que x.n. Uma ferramenta mais sofisticada é utilizada também nesta fase, o método SMIC-Prob-Expert (SMIC - Sistema de Matrizes de Impactos Cruzados), que é dividido em duas etapas:

1. Especialistas são consultados para avaliar a probabilidade de ocorrência das diversas hipóteses de cenários e, em seguida, respondem sobre a probabilidade das ocorrências, caso outras tenham ocorrido ou não - nesta fase, os especialistas avaliam a viabilidade das diversas hipóteses isoladamente, bem como a viabilidade elas em conjunto - considerando influências e interações.

2. As diversas respostas são compiladas e avaliadas estatisticamente, num processo que guarda certa similaridade com o método Delphi, de forma a selecionar cenários mais plausíveis e resgatar combinações inicialmente excluídas.

A fase seguinte identifica visões e projetos coerentes, quanto a opções estratégicas e possíveis ações, compatíveis tanto com a identidade da firma quanto com os mais prováveis cenários de seu ambiente. Essas opções / ações são então avaliadas contra os possíveis cenários desenvolvidos, utilizando-se uma ferramenta chamada MULTIPOL - Multicriteria Policy. Nesta ferramenta, cada ação é avaliada com respeito a cada critério definido: desenvolve-se inicialmente uma matriz em que são definidos pesos para cada combinação, como no exemplo a seguir:

\begin{tabular}{|l|l|l|l|l|}
\hline CRITÉRIO & $\mathbf{X}$ & $\mathbf{Y}$ & $\mathbf{Z}$ & \\
\hline
\end{tabular}


Revista Eletrônica de Ciência Administrativa (RECADM) - ISSN 1677-7387

\begin{tabular}{|c|c|c|c|c|}
\hline POLÍTICA & & & & $\Sigma$ \\
\hline A & 4 & 3 & 1 & 8 \\
\hline B & 1 & 4 & 5 & 10 \\
\hline C & 1 & 2 & 6 & 9 \\
\hline D & 2 & 2 & 1 & 5 \\
\hline
\end{tabular}

Quadro 4: Matriz de Impactos Cruzados (fonte: adaptado de Godet, 2000)

Em seguida, as ações são colocadas em um gráfico, que permite, através da ponderação obtida na matriz anterior, avaliá-las graficamente com relação às diversas políticas, como mostrado no exemplo a seguir:

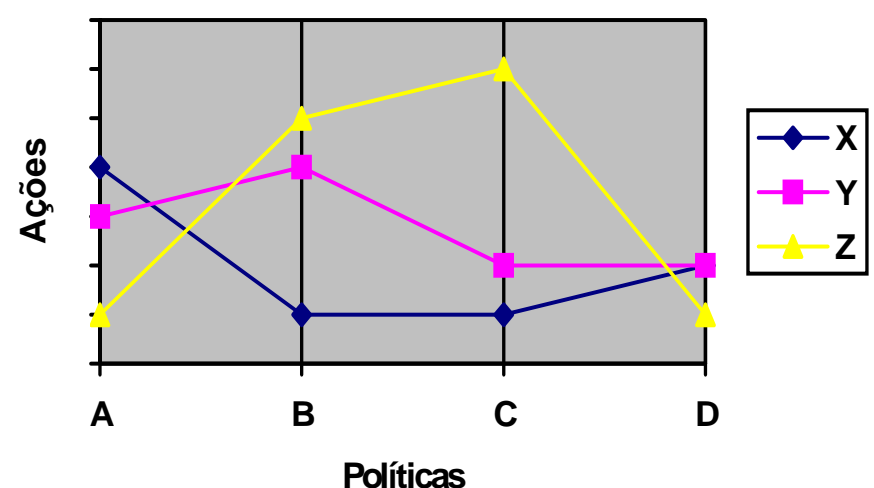

Figura 3: Ações de acordo com as diferentes políticas (fonte: Godet, 2000)

A fase seguinte, das escolhas estratégicas, caracteriza-se basicamente pelo movimento do pensamento para a ação, através da tomada de decisão pelo comitê gestor. E, em seguida, foca-se inteiramente na implementação dos planos de ação; isso envolve contratos de objetivos (negociados ou provocados), estabelecimento de um sistema de coordenação e acompanhamento interna e externa.

Há de se notar que o processo completo não segue uma progressão totalmente linear. Isso inclui diversos loops possíveis, particularmente entre a fase de definição das opções estratégicas e possíveis ações e a de diagnóstico da firma.

A implementação de planos de ação e resultados de observação estratégica e inteligência competitiva, pode levar, em certos casos, aos participantes do processo reconsiderarem a dinâmica da companhia em seu ambiente.

O uso de ferramentas específicas na abordagem de estratégia prospectiva estimula a imaginação, reduz inconsistências, cria uma linguagem comum, estrutura o pensamento coletivo e permite a apropriação pelos tomadores de decisão. No entanto, nenhuma ferramenta serve de substituta para a reflexão ou verificação na liberdade de escolha.

Os cenários tem diversas aplicações, conforme Davis (1998 e 2002a), Shell International (2001 e 2003) e Porter (1989): 
1. Ajudam a conectar os planos com a visão da organização - permitindo desafiar com maior clareza as premissas dos planos, comparar a visão e definir estratégias para lidar com macroriscos que virão;

2. Estabelecer uma linguagem comum e conceitos para pensar e falar sobre eventos correntes;

3. Concordar sobre o que é provável persistir ao longo do tempo estudado nos cenários e o que é fundamentalmente incerto;

4. Partindo das incertezas, identificar diferentes caminhos e desafios emergentes no ambiente de negócios global e preparar-se adequadamente, com políticas e estratégias;

5. Enriquecer o debate e ampliar a "conversa estratégica" na organização, trazendo novos conceitos e entendimento pelos usuários, alterando mapas mentais e desenvolvendo o foco nos desafios;

6. Forçam uma busca criativa de possíveis mudanças estruturais;

7. Buscar a "resiliência corporativa", incluindo tornar as decisões de risco mais transparentes. Isso envolve a identificação de ameaças e oportunidades e a criação e avaliação de opções;

8. Iniciar um processo formal de planejamento estratégico, incluindo o teste, o desenvolvimento e a avaliação das estratégias e planos existentes;

9. Estabelecer uma plataforma comum para prospecção, aprendizado e comunicação.

Conforme Porter (1989), uma empresa não sabe o cenário que vai ocorrer, logo ela deve escolher a melhor maneira de enfrentar a incerteza na seleção de sua estratégia, dados seus recursos e sua posição inicial. Um receita comum para enfrentar a incerteza é escolher uma estratégia "robusta", ou viável, independente do cenário que ocorra. Contudo, essa não é, de forma alguma, a única opção: uma empresa poderia decidir, em vez disso, preparar-se para um cenário, apesar do risco dele não ocorrer. Por outro lado, uma empresa com recursos maciços pode, algumas vezes, estar apta para seguir estratégias necessárias para lidar com todos os cenários simultaneamente e aguardar o desenrolar dos acontecimentos antes de enfocar seus esforços. Porter (1989) recomenda os seguintes métodos estratégicos a serem adotados, no que se refere aos cenários:

\begin{tabular}{|c|c|c|}
\hline Métodos & Características e Vantagens & Riscos \\
\hline $\begin{array}{lr}\text { Apostar } & \text { no } \\
\text { Cenário } & \text { Mais } \\
\text { Provável } & \end{array}$ & $\begin{array}{l}\text { Método mais comum para } \\
\text { formulação de estratégia, embora } \\
\text { feito implicitamente. }\end{array}$ & $\begin{array}{l}\text { Ocorrência de outros cenários, que tornem esta } \\
\text { estratégia inadequada, sendo difícil modificar a } \\
\text { estratégia no meio do processo. }\end{array}$ \\
\hline $\begin{array}{l}\text { Apostar no } \\
\text { Melhor } \\
\text { Cenário }\end{array}$ & $\begin{array}{l}\text { Projetar estratégia para o cenário } \\
\text { onde ela possa estabelecer a } \\
\text { vantagem competitiva mais } \\
\text { sustentável a longo prazo. }\end{array}$ & Idem acima. \\
\hline Garantir & $\begin{array}{l}\text { Escolher estratégia que produza } \\
\text { resultados satisfatórios em todos } \\
\text { os cenários, ou pelo menos em } \\
\text { cenários que julga terem maior } \\
\text { probabilidade de ocorrência. }\end{array}$ & $\begin{array}{l}\text { Normalmente produz uma estratégia que não é } \\
\text { ótima para nenhum cenário (sacrifício em } \\
\text { posição estratégica em favor de uma redução } \\
\text { de risco), além de quase sempre implicar em } \\
\text { custos mais altos. }\end{array}$ \\
\hline $\begin{array}{l}\text { Preservar } \\
\text { Flexibilidade }\end{array}$ & $\begin{array}{l}\text { Escolher uma estratégia que } \\
\text { preserve a flexibilidade até } \\
\text { tornar-se mais aparente o cenário } \\
\text { que irá de fato ocorrer, adiando } \\
\text { comprometimento de recursos } \\
\text { que a prendam a uma estratégia } \\
\text { em particular. }\end{array}$ & $\begin{array}{l}\text { Quase sempre a empresa paga um preço em } \\
\text { posição estratégica, devido às vantagens do } \\
\text { primeiro a se mover, obtidas por empresas que } \\
\text { comprometem-se antecipadamente. }\end{array}$ \\
\hline
\end{tabular}


Revista Eletrônica de Ciência Administrativa (RECADM) - ISSN 1677-7387

Faculdade Cenecista de Campo Largo - Coordenação do Curso de Administração

v. 3, n. 2, nov./2004 - http://revistas.facecla.com.br/index.php/recadm/

\begin{tabular}{|l|l|l|}
\hline Influenciar & $\begin{array}{l}\text { A empresa procura utilizar seus } \\
\text { recursos para gerar um cenário } \\
\text { que ela considera aconselhável. }\end{array}$ & $\begin{array}{l}\text { A possibilidade de influencia e seu custo devem } \\
\text { ser pesados contra a vantagem competitiva a } \\
\text { ser obtida se uma empresa aumentar as } \\
\text { probabilidades de ocorrência de seu cenário } \\
\text { preferido. }\end{array}$ \\
\hline
\end{tabular}

Quadro 5: Métodos Estratégicos sob Cenários (adaptado de Porter, 1989)

$\mathrm{Na}$ abordagem defendida por Buarque (2003) e também pelo Centro de Estudos Estratégicos (1997), os cenários constituem instrumentos úteis para apontar o panorama provável se nada for feito e podem ajudar a identificar quando e quais as medidas corretivas a serem tomadas. Sob este foco, 0 estudo "Dreaming with BRICs", publicado pela Goldman Sachs (WILSON \& PURUSHOTHAMAN, 2003), expõe a tendência favorável ao crescimento do Brasil, o que levaria o mesmo a se colocar como uma das seis maiores economias do mundo em 2050, junto aos EUA, Japão, Rússia, Índia e China. O estudo, desenvolvido basicamente com a utilização de tendências macroeconômicas, ainda que represente um futuro potencial único - contrário ao conceito de cenários múltiplos - indica as potenciais vantagens e dificuldades a serem encontradas pelo Brasil ao longo dos anos estudados. Tal abordagem tendencial, junto ao desenvolvimento de possíveis cenários futuros e opções estratégicas, poderia servir de base ao plano de desenvolvimento robusto e sustentável do país pelas próximas décadas.

A utilidade fundamental dos trabalhos com cenários consiste em cotejar os cenários prováveis com os cenários desejáveis e, com base nessa comparação, buscar discutir amplamente um projeto nacional de desenvolvimento de longo prazo que permita cobrir a distância do que somos para o que queremos ser.

\section{CONCLUSÕES}

Conforme citado no relatório People and Connections da Shell International (2001), os cenários auxiliam a empresa a focar nas incertezas críticas: o que não sabemos e que pode transformar o negócio e o que sabemos mas que pode envolver descontinuidades inesperadas. A chance de um cenário ocorrer exatamente como previsto é bastante diminuta, até mesmo para o mais provável cenário. Por exemplo, um cenário com 20 variáveis, assumindo-se que sejam independentes e cada uma tenha $90 \%$ de probabilidade de ocorrer, terá a probabilidade de ocorrer exatamente como previsto, em bases estritamente matemáticas, de somente 12\% (COATES, 2000). Os cenários não precisam ser absolutamente corretos - simplesmente precisamos ser menos "surpreendidos" do que aqueles que não praticam este pensamento (DAVIS, 1998). Cenários não são previsões, mas estórias alternativas factíveis e relevantes, que ajudam a explorar o "e se?" (what-if) e o "como?" (SHELL INTERNATIONAL, 2001). Conforme penetramos nestas estórias alternativas, somos guiados a praticar uma abordagem flexível para o futuro - preparado para as rupturas das tendências, pelo fato de ter experimentado diferentes cenários. Identificar as rupturas ou descontinuidades é um ponto central para as organizações, ajudando-as a se preparar para as mudanças. Uma organização aberta às mudanças é mais capaz de sobreviver e ter sucesso do que as que continuamente seguem os eventos. A meta é estar preparado para uma gama maior de eventualidades - idealmente 


\section{Revista Eletrônica de Ciência Administrativa (RECADM) - ISSN 1677-7387 Faculdade Cenecista de Campo Largo - Coordenação do Curso de Administração v. 3, n. 2, nov./2004 - http://revistas.facecla.com.br/index.php/recadm/}

interpretando como problemas normais o que os outros vêem como crises - e ter políticas de negócios que são melhores adaptadas para ambientes de negócios emergentes do que as dos competidores. O aprendizado que resulta dos cenários, guia a organização para estratégias mais robustas, um claro senso de direção e ações mais efetivas (DAVIS, 1998). Ou ainda, como citado por Watts (2002), o importante não é prover as respostas - as quais são pouco prováveis de estarem corretas - mas gerar as questões, desafiando premissas e colocando novas considerações na agenda. Bethlem (1999) cita a avaliação ambiental e as técnicas de elaboração de cenários como exercícios úteis e recomendáveis: ainda que nunca vá se prever o futuro com precisão, nem ajustarse otimamente às condições do ambiente, se estará melhor preparado para enfrentar os futuros possíveis e não previstos ao se exercitar o cérebro a pensar em futuros alternativos. Tais conceitos foram validados durante as entrevistas com os especialistas em cenários prospectivos: ainda que as metodologias, duração e processo de informação e desdobramento de ações, variassem nas experiências relatadas, encontraram-se os seguintes pontos comuns e recomendações:

1. O uso de especialistas de diversas áreas na geração dos possíveis cenários;

2. O uso de ferramentas analíticas para identificação dos atores e seu poder de influência;

3. As mudanças na forma de pensar e agir dos atores em situações diferentes das atualmente conhecidas, bem como suas interações;

4. O uso do brainstroming - geral ou por grupos;

5. Coleta de informações internas e externas;

6. O uso de rodadas múltiplas, seja no brainstroming, Delphi, ou qualquer outro processo de geração e validação de alternativas;

7. Comprometimento da Alta Direção para sustentação dos estudos e utilização dos cenários;

8. A importância da constância de revisão, análise e correção de rumos nos estudos de cenários, inclusive, devendo ser pensado como um núcleo permanente - não esporádico - de sustentação estratégica de decisões;

9. Dificuldade encontrada pelos especialistas não familiarizados com o conceito de cenários prospectivos - por conta do entendimento da importância e potencial dos mesmos;

10. Difícil equilíbrio da memória - fatos ocorridos e tendências - com a abstração e criatividade e extrapolação dos limites atualmente conhecidos e entendidos como normais;

11. Necessidade da percepção de mudança nos diversos níveis - rotineiros e/ou estruturais;

12. Forte foco na manutenção do processo de geração de cenários;

13. Ter em mente que o uso dos cenários se dará no nível de definição estratégica e não somente na geração de plano de contingências;

14. Estar sempre aberto às situações de ruptura;

15. Necessidade de gerir a disseminação das decisões, buscando o entendimento e comprometimento vs. a imposição;

16. Necessidade de documentação - memória para suporte às decisões;

17. Qualquer que seja a metodologia, deve ser tratado como investimento estratégico, e não como custo; 
18. É válido o uso da intuição, que junto aos métodos científicos permite a validação: a ciência diminui o risco da intuição, mas não pode ser uma "camisa de força";

19. É pouco provável que se acerte os cenários, exatamente como vão ocorrer. No entanto, o estudo em si permite à organização traçar as possibilidades e enxergar os riscos e oportunidades existentes: o uso dos cenários permite o pensamento estratégico e a capacitação da organização de gerir apropriadamente no futuro, preparando-se desde já para ele, ainda que desconhecido.

Considerando os objetivos específicos do presente trabalho, a exposição dos fundamentos teóricos que abordam de forma mais direta o entendimento, estruturação e utilização dos cenários prospectivos como instrumentos de proposição e monitoramento de estratégias, conclui-se que a utilização de cenários prospectivos mostra-se uma ferramenta que pode auxiliar a definir a estratégia da organização, permitindo ao mesmo tempo, uma posição mais flexível e apropriada para lidar com a incerteza e o novo, tornando-a mais robusta no posicionamento estratégico.

A evolução do presente trabalho poderia conter informações adicionais referentes ao detalhamento do processo de construção e uso de cenários, de forma a poder ser utilizado pelas pessoas e organizações interessadas no tema, servindo à função de um "Manual de Implementação e Uso", o que facilitaria a proliferação do conhecimento e, consequentemente, dos benefícios advindos da utilização de cenários prospectivos como ferramentas e instrumentos de proposição e ação, além do monitoramento, das ações estratégicas de obtenção e manutenção de posições competitivas.

\section{REFERÊNCIAS}

ARCADE, JACQUES et al. Structural Analysis with the MICMAC Method \& Actor's Strategy with MACTOR Method, Future Research Methodology, Laboratory for Investigation in Prospective and Strategy (LIPS), Paris, 2003.

BARROS, NELCI. Vigília Tecnológica e Descontinuidades na Criação de Produtos - Uma Proposta de Método para a Pratica de Prospeccão Tecnológica, 2000. Tese de Doutorado em Engenharia de Produção. Universidade Federal de Santa Catarina - UFSC, Programa de PósGraduação em Engenharia de Produção, Florianópolis/SC.

BETHLEM, AGRICOLA. Estratégia Empresarial - Conceitos, Processos e Administração Estratégica, 2a. Edição, São Paulo: Editora Atlas, 1999.

BRAINSTORMING, Método Grumbach, Brainstorming Assessoria de Planejamento e Informática. Disponível em http://www.brainstorming.com.br/textos/Metodo.htm. Acesso em 22 dez 2003.

BRASIL, MINISTÉRIO DO DESENVOLVIMENTO, INDÚSTRIA E COMÉRCIO EXTERIOR, Curso de Capacitação de Equipes em Estudos Prospectivos de Cadeias Produtivas, [2001?], Programa Brasileiro de Prospectiva Tecnológica Industrial, Biblioteca, Documentos para Pesquisa. Disponível em http://www.mdic.gov.br/tecnologia/prospectiva/ptiBiblioteca.htm. Acesso em 22 dez 2003.

BUARQUE, SÉRGIO. Metodologia e Técnicas de Construção de Cenários Globais e Regionais. Texto para Discussão no. 939, IPEA - Instituto de Pesquisa Econômica Aplicada, Ministério do Planejamento, Orçamento e Gestão. Brasília, 2003. 
Revista Eletrônica de Ciência Administrativa (RECADM) - ISSN 1677-7387

CENTRO DE ESTUDOS ESTRATÉGICOS, Cenários Brasil 2020, Revista Parcerias Estratégicas, vol. 1, no. 3, junho 1997, Centro de Estudos Estratégicos, Ministério da Ciência e Tecnologia, Brasília, 1997.

COATES, JOSEPH. Scenario Planning, Technological Forecasting and Social Change, Elsevier Science Inc, New York, 2000.

DAVIS, GED. Creating Scenarios for Your Company's Future. Shell International, The 1998 Conference on Corporate Environmental, Health, and Safety Excellence - Bringing Sustainable Development Down to Earth. New York/NY, 1998.

DAVIS, GED. Questioning Assumptions - Exploring Alternative Business Futures, Swedbank Conference, Stockolm, 2002a.

DAVIS, GED. Scenarios as Tool for the $21^{\text {st }}$ Century - Probing the Future Conference, Strathclyde University, Glasgow, Scotland, 2002b.

GODET, MICHEL et al. Scenarios and Strategies: A Toolbox for Scenario Planning, 1999. Cahiers du LIPS - Laboratory for Investigation in Prospective and Strategy. Disponível em http://www.cnam.fr/deg/lips/toolbox/toolbox2.html. Acesso em 10 nov. 2003.

GODET, MICHEL. The Art of Scenarios and Strategic Planning: Tools and Pitfalls, Technological Forecasting and Social Change, Elsevier Science Inc, New York, 2000.

GODET, MICHEL; ROUBELAT, FABRICE. Scenario Planning: An Open Future, Technological Forecasting and Social Change, Elsevier Science Inc, New York, 2000.

JOUVENEL, HUGUES. A Brief Methodological Guide to Scenario Building, Technological Forecasting and Social Change, Elsevier Science Inc, New York, 2000.

MARCIAL, ELAINE. Aplicação de Metodologia de Cenários no Banco do Brasil no Contexto da Inteligência Competitiva, 1999. Université de Droite et des Sciences D’Aix, Faculté des Sciences et Techniques de Saint-Jérome, Centre de Recherces Rétrospectives de Marseille. Dissertação de DEA em Inteligência Competitiva. Marseille, France.

MARCIAL, ELAINE; COSTA, ALFREDO. E O Mundo Não Acabou: O Uso de Cenários Prospectivos e Inteligência Competitiva - Caso do Bug 2000 no Banco do Brasil, 2001. Anais do II Workshop Brasileiro de Inteligência Competitiva e Gestão do Conhecimento. Florianópolis/SC.

MASINI, ELEONORA; VASQUEZ, JAVIER. Scenario as Seen from Human and Social Perspective, Technological Forecasting and Social Change, Elsevier Science Inc, New York, 2000.

PORTER, MICHAEL. Vantagem Competitiva: Criando e Sustentando um Desempenho Superior. Rio de Janeiro: Editora Campus, 1989.

ROUBELAT, FABRICE, Scenario Planning as a Networking Process, Technological Forecasting and Social Change, Elsevier Science Inc, New York, 2000.

SHELL INTERNATIONAL. People and Connections - Global Scenarios to 2020 - Public Summary. Global Business Environment, Shell International Limited. London, 2001.

SHELL INTERNATIONAL. Latin America - Scenarios to 2020, Exploring the Future, Shell International Limited. London, 2002.

SHELL INTERNATIONAL. Scenarios: An Explorer's Guide, Exploring the Future, Shell International Limited. London, 2003. 
Revista Eletrônica de Ciência Administrativa (RECADM) - ISSN 1677-7387 Faculdade Cenecista de Campo Largo - Coordenação do Curso de Administração v. 3, n. 2, nov./2004 - http://revistas.facecla.com.br/index.php/recadm/

VAN DER HEIJDEN, KEES. Scenarios and Forecasting: Two Perspectives, Technological Forecasting and Social Change, Elsevier Science Inc, New York, 2000.

WATTS, PHILIP. Remarks at the Launch of People and Connections - Global Scenarios to 2020. Royal Dutch / Shell Group, London, 2002.

WILLIANS, CHRIS, Building the Toolbox - England, Organization for Economic Co-operation and Development, Document no. 04, OECD Forum on Schooling for Tomorrow at The Institute International de la Prospective, Futuroscope, Pointiers, France, 2003.

WILSON, DOMINIC; PURUSHOTHAMAN, ROOPA. Dreaming with BRICs: The Path to 2050, 2003. Goldman Sachs, Global Economics Paper no. 99. Disponível em http://www.gs.com. Acesso em 27 out. 2003.

ZUMBLE. Planejamento por Cenários e Pensamento Sistêmico, 2000. Zumble Aprendizagem Organizacional. Apresentação em Power Point. 